\title{
A 10-year analysis of microbiological profiles of microbial keratitis: the North East England Study
}

\author{
Darren Shu Jeng Ting $\mathbb{1}^{1} \cdot$ Chris Settle ${ }^{2} \cdot$ Stephen J. Morgan ${ }^{1} \cdot$ Oliver Baylis ${ }^{1} \cdot$ Saurabh Ghosh ${ }^{1}$
}

Received: 27 February 2018 / Accepted: 13 March 2018 / Published online: 3 April 2018

(c) The Royal College of Ophthalmologists 2018

Tan et al. [1] recently reported a 12-year analysis of microbial keratitis in a tertiary eye centre (Manchester) in which they found a significant decreasing trend in Gram-positive keratitis along with an increasing trend in Moraxella keratitis. According to the literature and our experience, Moraxella keratitis is known for its chronicity and slow response to treatment $[2,3]$. In view of their findings, we performed a 10year retrospective analysis (January 2008-December 2017) on the microbiological profiles of microbial keratitis in Sunderland Eye Infirmary (one of the three main eye centres in the North East of England) to determine if the changing trend of microbial keratitis was similar across the UK.

During our study period, a total of 407 positive corneal scrapes (out of 914 scrapes) were identified, giving a yield rate of $44.5 \%$. Of 407 cases, $212(52.1 \%)$ were female and mean age was 55.9 (SD 21.0) years; 57 (14.0\%) cases were polymicrobial. A total of 478 organisms were isolated; these included 308 (64.9\%) Gram-positive and 127 (26.2\%) Gramnegative organisms, 20 (4.2\%) fungal, and 23 (4.8\%) acanthamoeba. For descriptive and analytic purposes, the study was divided into two time periods, namely 2008-2012 and 2013-2017. We observed a similar increasing trend in Moraxella keratitis, although statistical significance was not achieved. However, there was an increasing trend in Gram-positive organisms, particularly coagulase-negative staphylococci, and a decreasing trend in Gram-negative organisms, particularly pseudomonas, in our region (Table 1). Reassuringly we only identified two $(0.5 \%)$ cases of methicillin-resistant staphylococcus aureus (MRSA) over the past 10 years. This was in contrast to the considerably high prevalence of MRSA-related

Darren Shu Jeng Ting

ting.darren@gmail.com

1 Sunderland Eye Infirmary, Queen Alexandra Road, Sunderland SR2 9HP, UK

2 Department of Microbiology, Sunderland Royal Hospital, Sunderland, UK ocular infection reported in other countries [4]. In addition, acanthamoeba keratitis was more commonly associated with patients of younger age group as compared to those with Grampositive, Gram-negative and fungal keratitis (Table 2). This was most likely related to the use of contact lens in younger patients.

Our study supports the inherent nature of geographical and temporal variations of microbiological profiles of

Table 1 Summary of microbiological profiles of microbial keratitis in Sunderland Eye Infirmary between 2008-2012 and 2013-2017

\begin{tabular}{llll}
\hline Organisms & $\begin{array}{l}2008-2012 \\
N=209 ; N(\%)\end{array}$ & $\begin{array}{l}2013-2017 \\
N=269 ; N(\%)\end{array}$ & $P$-value \\
\hline Gram-positive & $125(59.8)$ & $183(68.0)$ & 0.063 \\
Streptococcus & $32(25.6)$ & $26(14.2)$ & $\underline{0.012}$ \\
S. aureus & $33(26.4)$ & $32(17.5)$ & 0.060 \\
CoNS & $40(32.0)$ & $84(45.9)$ & 0.015 \\
Bacillus & $11(8.8)$ & $21(11.5)$ & 0.450 \\
Others & $9(7.2)$ & $10(5.5)$ & 0.534 \\
Gram-negative & $65(31.1)$ & $62(23.0)$ & 0.048 \\
Pseudomonas & $31(47.7)$ & $19(30.6)$ & 0.049 \\
Moraxella & $19(29.2)$ & $26(41.9)$ & 0.135 \\
Others & $15(23.1)$ & $17(27.4)$ & 0.573 \\
Fungi & $12(5.7)$ & $8(3.0)$ & 0.134 \\
Yeast & $5(41.7)$ & $5(62.5)$ & 0.361 \\
Filamentous & $7(58.3)$ & $3(37.5)$ & 0.361 \\
Acanthamoeba & $7(3.4)$ & $16(6.0)$ & 0.188 \\
\hline
\end{tabular}

Chi-square test was used to detect any significant changing trend of the microbiological profiles between the two time periods. Significant $P$ values ( 0.05) are underlined. The calculation of the proportions of organisms was performed at two levels; the first level comprised Gram-positive and Gram-negative organisms, fungi and acanthamoeba; and the second level comprised the subtypes of the organisms within the four groups

CoNS coagulase-negative staphylococcus

${ }^{a}$ Other Gram-positive organisms included Aerococcus, Enterococcus, Kocuria, Micrococcus, Mycobacterium and Rothia

${ }^{\mathrm{b}}$ Other Gram-negative organisms included Acinetobacter, Aeromonas, Burkholderia, Haemophilus, Klebsiella, Neisseria, Ochrobactrum, Raoultella, Serratia, Sphingomonas and Stenotrophomonas 
Table 2 Association of age and gender with the microbiological profiles of microbial keratitis

\begin{tabular}{llllr}
\hline & $\begin{array}{l}\text { Gram-positive } \\
(N=309)\end{array}$ & $\begin{array}{c}\text { Gram-negative } \\
(N=126)\end{array}$ & $\begin{array}{c}\text { Fungi } \\
(N=20)\end{array}$ & $\begin{array}{c}\text { Acanthamoeba } \\
(N=23)\end{array}$ \\
\hline $\begin{array}{l}\text { Age, years } \\
\text { Gender, } N(\%)\end{array}$ & $56.3(21.1)$ & $57.6(20.4)$ & $55.3(21.8)$ & $34.4(12.9)$ \\
Female & $151(48.9)$ & $60(47.6)$ & $7(35.0)$ & $14(60.9)$ \\
Male & $158(51.1)$ & $66(52.4)$ & $13(65.0)$ & $9(39.1)$ \\
\hline
\end{tabular}

Age is presented in mean (SD). One-way ANOVA test was used to analyse the mean differences and $\chi^{2}$ test was used to analyse the categorical variables between the four groups. Significant $P$-value $(<0.05)$ is underlined

microbial keratitis in different regions, including the UK [5]. This highlights the importance of up-to-date examination of microbial keratitis in a particular region.

\section{Compliance with ethical standards}

Conflict of interest The authors declare that they have no conflict of interest.

\section{References}

1. Tan SZ, Walkden A, Au L, Fullwood C, Hamilton A, Qamruddin A, et al. Twelve-year analysis of microbial keratitis trends at a UK tertiary hospital. Eye (Lond). 2017;31:1229-36.

2. Inoue $H$, Suzuki $T$, Inoue $T$, Hattori $T$, Nejima $R$, Todokoro $D$, et al. Clinical characteristics and bacteriological profile of Moraxella keratitis. Cornea. 2015;34:1105-9.

3. Das S, Constantinou M, Daniell M, Taylor HR. Moraxella keratitis: predisposing factors and clinical review of 95 cases. Br J Ophthalmol. 2006;90:1236-8.

4. Asbell PA, Sanfilippo CM, Pillar CM, DeCory HH, Sahm DF, Morris TW. Antibiotic resistance among ocular pathogens in the United States: five-year results from the Antibiotic Resistance Monitoring in Ocular Microorganisms (ARMOR) Surveillance Study. JAMA Ophthalmol. 2015;133:1445-54.

5. Shah A, Sachdev A, Coggon D, Hossain P. Geographic variations in microbial keratitis: an analysis of the peer-reviewed literature. $\mathrm{Br}$ J Ophthalmol. 2011;95:762-7.

\title{
Response to: A 10-year analysis of microbiological profiles of microbial keratitis: the North East England study
}

\author{
A Walkden ${ }^{1,2} \cdot \mathrm{S} \mathrm{Z} \operatorname{Tan}^{1,2} \cdot \mathrm{L} \mathrm{Au}^{1,2} \cdot \mathrm{A} \mathrm{K} \mathrm{Brahma}{ }^{1,2} \cdot \mathrm{F} \mathrm{Carley}^{1,2}$ \\ Received: 13 March 2018 / Accepted: 13 March 2018 / Published online: 3 April 2018 \\ (c) The Royal College of Ophthalmologists 2018
}

A Walkden

walkdenandrew@gmail.com

1 Centre for Ophthalmology and Vision Sciences, Faculty of Medical and Human Sciences, University of Manchester, Manchester, UK

2 Manchester Royal Eye Hospital, Central Manchester University Hospitals NHS Foundation Trust, Manchester Academic Health Science Centre, Manchester M13 9WL, UK
Many thanks for alerting us to the microbiological profiles of microbial keratitis from our colleagues in the North East of England study. As our article had urged other authors to analyse their own local microbial data, we are delighted to see this work being undertaken in other areas of the UK.

This data highlights the need for individual local analysis in order to tailor appropriate antibiotic therapy. Similar rates of bacteria, fungi, and acanthamoeba are seen across the two centres. Indeed the increasing trend in gram positive pathogens, less than 150 miles from our centre is interesting. A similar but not statistically significant trend was seen 